\title{
Expression of glucose transporter 1 and prognosis in non-small cell lung cancer: a pooled analysis of 1665 patients
}

\author{
Zhibo Tan', Chao Yang ${ }^{2}$, Xiaohan Zhang ${ }^{2}$, Pingju Zheng ${ }^{1}$ and Weixi Shen ${ }^{1}$ \\ ${ }^{1}$ Department of Oncology, Shenzhen Hospital of Southern Medical University, Shenzhen 518110, Guangdong, PR China \\ ${ }^{2}$ Department of Gastroenterology, Shenzhen Hospital of Southern Medical University, Shenzhen 518110, Guangdong, PR \\ China
}

Correspondence to: Weixi Shen, email: shenweixiszh@sohu.com

Keywords: GLUT1, meta-analysis, overall survival, prognosis

Received: March 06, $2017 \quad$ Accepted: April 15, $2017 \quad$ Published: May 04, 2017

Copyright: Tan et al. This is an open-access article distributed under the terms of the Creative Commons Attribution License 3.0 (CC BY 3.0), which permits unrestricted use, distribution, and reproduction in any medium, provided the original author and source are credited.

\section{ABSTRACT}

Glucose transporter 1 (GLUT1) plays an important role in the transport and metabolism of glucose in cancer cells. An increasing number of studies have explored the connection between GLUT1 expression and prognosis in non-small cell lung cancer (NSCLC), but the results have been controversial. Therefore, we conducted a metaanalysis to obtain a comprehensive evaluation of the prognostic value of GLUT1 in NSCLC. Relevant studies from PubMed, Embase, and Web of Science were searched. Hazard ratios (HRs) and odds ratios (ORs) with their $95 \%$ confidence intervals (CIs) were used as the effective measures. A total of 10 studies involving 1,665 patients were included in this meta-analysis. The results showed that GLUT1 overexpression was associated with poor overall survival ( $\mathrm{HR}=2.21 ; 95 \% \mathrm{CI}, 1.42-3.42 ; \mathrm{p}<0.001)$ and disease-free survival ( $H R=1.73 ; 95 \% \mathrm{CI}, 1.35-2.23 ; \mathrm{p}<0.001)$. Furthermore, elevated GLUT1 expression correlated with sex (OR $=2.29 ; 95 \%$ CI, 1.17-4.49; $p=0.015)$, advanced tumor stage $(O R=2.46 ; 95 \% C I, 1.79-3.38 ; p<0.001)$, histology (OR = 6.99; 95\% CI, 4.71-10.38; p < 0.001), and large tumor size (OR = 2.77; 95\% CI, 1.73-4.44; $\mathrm{p}<0.001$ ). This meta-analysis revealed overexpression of GLUT1 to be a biomarker of worse prognosis in NSCLC.

\section{INTRODUCTION}

Lung cancer is a lethal cancer with the highest incidence among all cancer types worldwide [1]. Nonsmall cell lung cancer (NSCLC) accounts for approximately $85 \%$ of all lung cancer cases [2]. In recent years, great progresses have been made in terms of treatment strategies for NSCLC [3, 4]; however, long-term survival remains unsatisfactory with a 5 -year survival rate as low as $16.3 \%[2$, 5]. The fact that prognostic parameters are lacking is one important reason for the disappointing prognosis [5]. Several clinical features, including pathological stage, gene mutational status [4], and smoking history have been used as biomarkers for prognostication. However, they only provide crude measures of the aggressiveness of NSCLC. Therefore, novel biological markers are still needed.

Glucose is the major source of energy for cells [6]. Compared to normal cells, cancer cells often have higher rates of glucose metabolism to support their rapid proliferation [7]. The glucose transporter (GLUT) family is responsible for glucose uptake [8]. The GLUT family is a collection of 14 membrane proteins [8], among which glucose transporter 1 (GLUT1, also known as SLC2A1) was the first to be cloned and has been the most extensively studied [9]. GLUT1 overexpression has been reported in a large variety of malignancies, including prostate cancer, thyroid cancer, gastric cancer, head and neck cancer, and NSCLC [6]. Previous studies [10-12] have presented controversial and even contrary results regarding the prognostic role of GLUT1 in NSCLC. For example, Minami et al. [10] showed that GLUT1 expression was a prognostic factor for poor survival; however, Osugi et al. [13] reported no significant correlation between GLUT1 and overall survival (OS) in NSCLC. These inconsistent results may be caused by the limited sample sizes in each single study. Therefore, we conducted a meta-analysis to clarify the prognostic significance of GLUT1 expression in NSCLC. 


\section{RESULTS}

\section{Study selection process and characteristics of included studies}

The selection process of eligible studies is shown in Figure 1. Initial electronic search identified 1228 records, and after duplicates were removed, 927 remained for selection. A total of 891 records were excluded by title/abstract screening. Subsequently, 36 studies were evaluated by full-text reading. Twentysix studies were further excluded because of inadequate data, absence of immunohistochemistry (IHC) method, being a meeting abstract, or not published in English. Finally, a total of 10 studies [10-19] involving 1,665 patients were included in the meta-analysis. The baseline characteristics of the included studies are listed in Table 1. Six studies [10, 12, 13, 15, 17, 18] were from Japan, and one each from Norway [11] The Netherlands [14] Greece [16], and Korea [19]. All included studies employed retrospective study designs, and were of high quality with Newcastle-Ottawa Scale (NOS) scores of 7 to 9 .

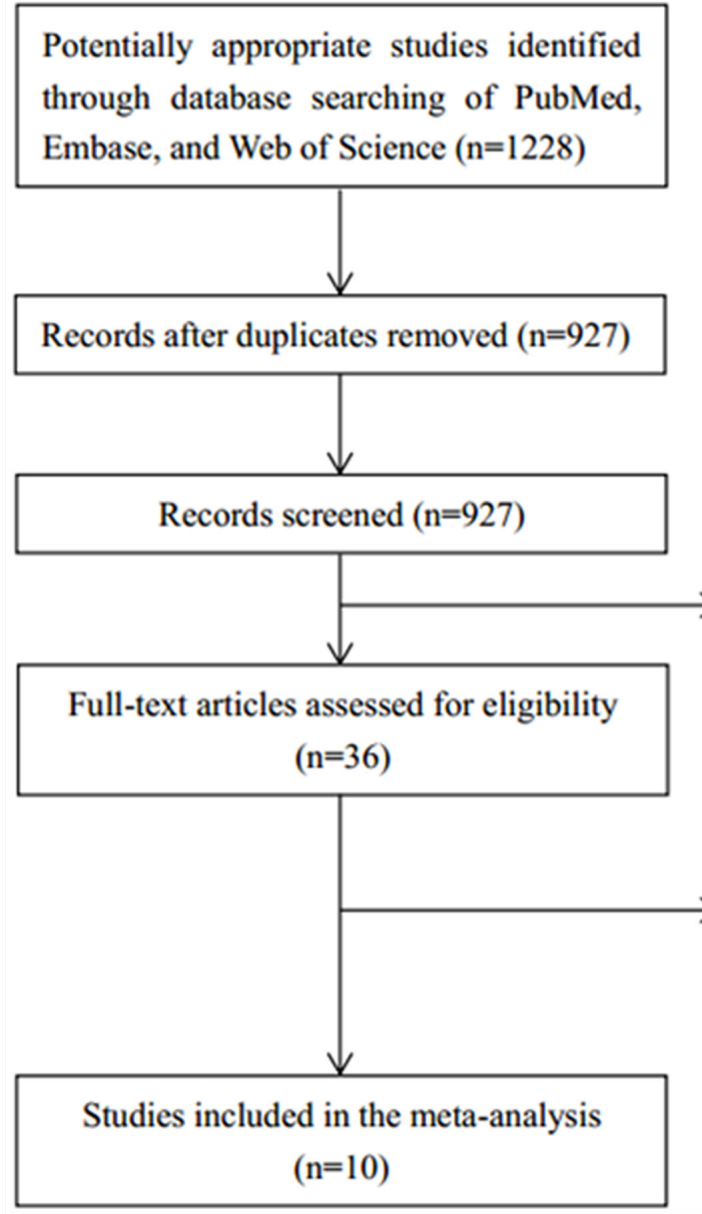

\section{Correlation of GLUT-1 with overall survival}

A total of eight studies containing 1,246 patients explored the relationship between GLUT1 expression and OS. The pooled HR was 2.21 with a $95 \%$ CI of 1.42 3.42 ( $\mathrm{p}<0.001$; Table 2, Figure 2), although significant heterogeneity $\left(I^{2}=66.6 \% ; \mathrm{P}_{\mathrm{h}}=0.004\right)$ was detected. Subgroup analysis stratified by ethnicity showed that high GLUT1 expression remained a significant indicator for poor OS in Asian patients ( $\mathrm{HR}=2.48$; 95\% CI, 1.54 $3.99 ; \mathrm{p}<0.001$; Table 2, Figure 2); however, no significant association was found for Caucasian patients $(\mathrm{HR}=1.2$; $95 \%$ CI, 0.72-2.00; $\mathrm{p}=0.485$; Table 2, Figure 2).

\section{Association between GLUT1 and disease-free survival}

Pooled data from six studies with 1,060 patients with no heterogeneity $\left(I^{2}=0 ; \mathrm{P}_{\mathrm{h}}=0.58\right)$ indicated that GLUT1 expression was predictive for poor disease-free survival (DFS) (HR $=1.73$; 95\% CI, 1.35-2.23; $<<0.001$; Table 2, Figure 3). Subgroup analysis demonstrated that GLUT1 was still a biomarker for poor DFS in both Asian
Records excluded after title/abstract review $(\mathrm{n}=891)$

Articles excluded $(\mathrm{n}=26)$ with reasons: Insufficient data on survival $(\mathrm{n}=17)$

Not study on NSCLC $(n=3)$

Meeting abstract $(n=2)$

No IHC method $(\mathrm{n}=2)$

Not study on GLUT1 $(n=1)$

No English article $(\mathrm{n}=1)$

Figure 1: Flow chart demonstrating those studies that were processed for inclusion in the meta-analysis. 
Table 1: Characteristics of the included studies.

\begin{tabular}{|c|c|c|c|c|c|c|c|c|c|c|c|c|c|}
\hline Study & Year & Country & Ethnicity & $\begin{array}{c}\text { Age(years) } \\
\text { median(range) }\end{array}$ & $\begin{array}{c}\text { Histological } \\
\text { type }\end{array}$ & $\begin{array}{l}\text { Sample } \\
\text { size }\end{array}$ & $\begin{array}{c}\text { Gender } \\
(\mathbf{M} / \mathbf{F})\end{array}$ & Study design & $\begin{array}{c}\text { Tumor } \\
\text { stage }\end{array}$ & $\begin{array}{l}\text { Study } \\
\text { period }\end{array}$ & Method & $\begin{array}{l}\text { NOS } \\
\text { score }\end{array}$ & $\begin{array}{l}\text { Outcome } \\
\text { measured }\end{array}$ \\
\hline Minami & 2002 & Japan & Asian & $64(41-81)$ & Adenocarcinoma & 47 & $28 / 19$ & Retrospective & I & $\begin{array}{l}1991- \\
1997\end{array}$ & IHC & 9 & OS \\
\hline Andersen & 2011 & Norway & Caucasian & $67(28-85)$ & Mixed & 335 & $253 / 82$ & Retrospective & I -III & $\begin{array}{l}1990- \\
2004\end{array}$ & $\mathrm{IHC}$ & 8 & DFS \\
\hline Kaira & 2011 & Japan & Asian & $67(39-89)$ & Mixed & 160 & $97 / 63$ & Retrospective & I -III & $\begin{array}{l}2002- \\
2004\end{array}$ & IHC & 7 & OS \\
\hline Meijer & 2012 & $\begin{array}{l}\text { The } \\
\text { Netherlands }\end{array}$ & Caucasian & NR & Mixed & 84 & $51 / 33$ & Retrospective & I -III & $\begin{array}{l}2002- \\
2008\end{array}$ & $\mathrm{IHC}$ & 8 & DFS \\
\hline Sasaki & 2012 & Japan & Asian & $65(29-86)$ & Mixed & 283 & $189 / 94$ & Retrospective & I -IV & $\begin{array}{l}2001- \\
2008\end{array}$ & $\mathrm{IHC}$ & 8 & OS \\
\hline Karpathiou & 2013 & Greece & Caucasian & $67(28-83)$ & Mixed & 115 & $103 / 12$ & Retrospective & I -IV & NR & $\mathrm{IHC}$ & 8 & OS \\
\hline Maki & 2013 & Japan & Asian & $65(29-83)$ & Adenocarcinoma & 105 & $49 / 56$ & Retrospective & I & $\begin{array}{l}2004- \\
2006\end{array}$ & IHC & 7 & OS/DFS \\
\hline Furukawa & 2015 & Japan & Asian & 65 & Mixed & 133 & $90 / 43$ & Retrospective & I -III & $\begin{array}{l}2007- \\
2010\end{array}$ & IHC & 8 & OS/DFS \\
\hline Osugi & 2015 & Japan & Asian & $70(48-87)$ & Mixed & 134 & $92 / 42$ & Retrospective & I -III & $\begin{array}{l}1998- \\
2000\end{array}$ & $\mathrm{IHC}$ & 8 & OS/DFS \\
\hline Koh & 2017 & Korea & Asian & $64(35-86)$ & Mixed & 269 & $189 / 80$ & Retrospective & I -III & $\begin{array}{l}2009- \\
2013\end{array}$ & $\mathrm{IHC}$ & 8 & OS/DFS \\
\hline
\end{tabular}

Abbreviations: IHC, immunohistochemistry; NR, not reported; OS, overall survival; DFS, disease-free survival; NOS, Newcastle-Ottawa Scale.

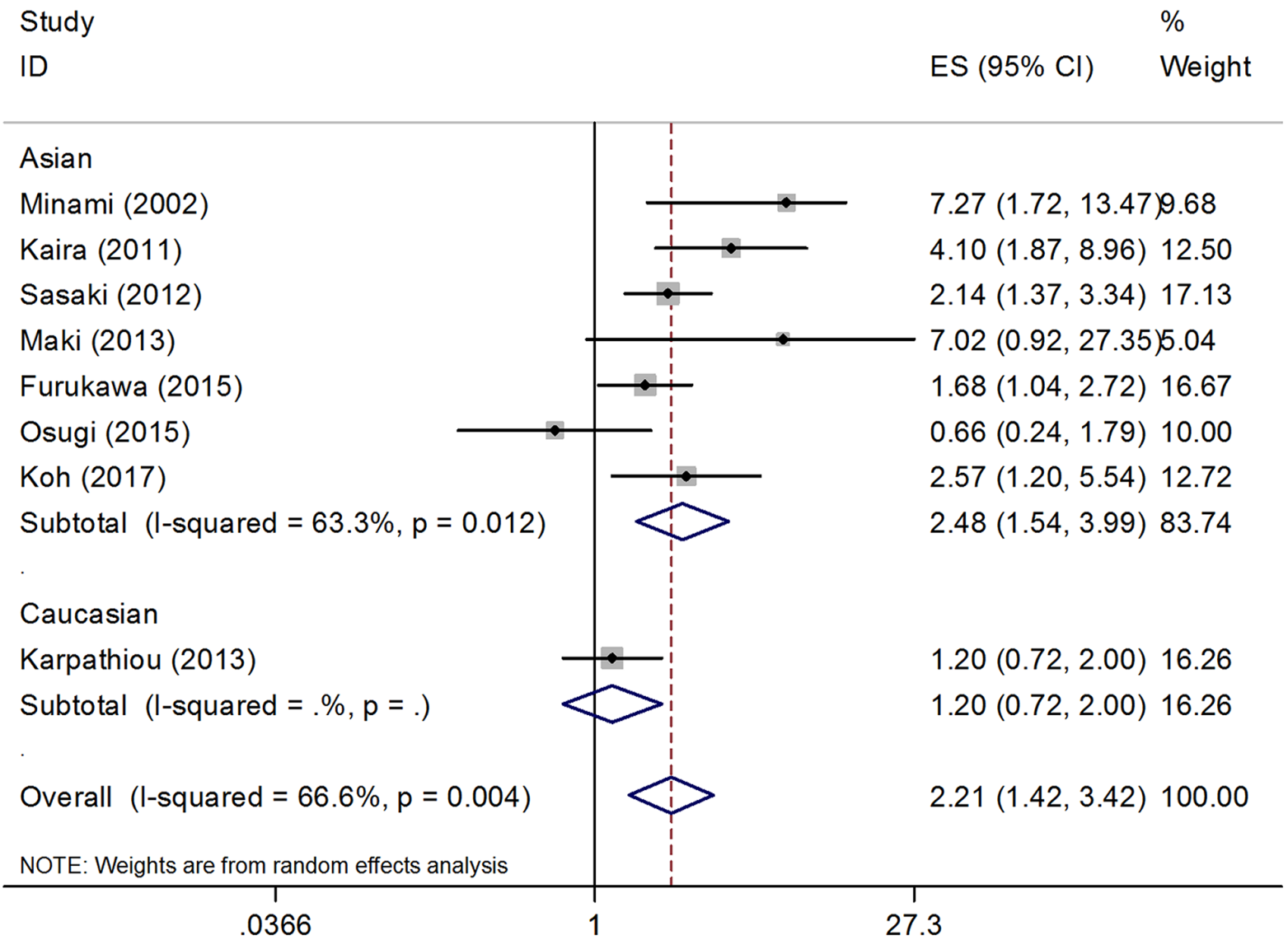

Figure 2: Forest plot of the association between GLUT1 and OS, subgroup analysis was stratified by ethnicity. 
Table 2: Meta-analysis: HR values of OS and DFS in NSCLC subgroups according to patient source.

\begin{tabular}{|c|c|c|c|c|c|c|c|}
\hline \multirow[t]{2}{*}{ Factors } & \multirow[t]{2}{*}{ No. of studies } & \multirow[t]{2}{*}{ No. of patients } & \multirow[t]{2}{*}{ Effects model } & \multirow[t]{2}{*}{ HR $(95 \% C I)$} & \multirow[t]{2}{*}{$\mathbf{p}$} & \multicolumn{2}{|c|}{ Heterogeneity } \\
\hline & & & & & & $I^{2}(\%)$ & $\mathbf{P}_{\mathrm{h}}$ \\
\hline Overall for OS & 8 & 1246 & REM & $2.21(1.42-3.42)$ & $<0.001$ & 66.6 & 0.004 \\
\hline \multicolumn{8}{|l|}{ Ethnicity } \\
\hline Asian & 7 & 1131 & REM & $2.48(1.54-3.99)$ & $<0.001$ & 63.3 & 0.012 \\
\hline Caucasian & 1 & 115 & - & $1.2(0.72-2)$ & 0.485 & - & - \\
\hline Overall for DFS & 6 & 1060 & FEM & $1.73(1.35-2.23)$ & $<0.001$ & 0 & 0.58 \\
\hline \multicolumn{8}{|l|}{ Ethnicity } \\
\hline Asian & 4 & 641 & FEM & $1.61(1.2-2.16)$ & 0.001 & 0 & 0.479 \\
\hline Caucasian & 2 & 419 & FEM & $2.16(1.3-3.57)$ & 0.003 & 0 & 0.558 \\
\hline
\end{tabular}

$(\mathrm{HR}=1.61 ; 95 \% \mathrm{CI}, 1.2-2.16 ; \mathrm{p}=0.001)$ and Caucasian $(\mathrm{HR}=2.16 ; 95 \% \mathrm{CI}, 1.3-3.57 ; \mathrm{p}=0.003)$ patients.

\section{Correlation of GLUT-1 with clinicopathological parameters}

The association between GLUT1 and six clinicopathological parameters were investigated. The clinicopathological parameters were sex (male vs. female), tumor stage (III - IV vs. I - II), age ( $\geq 65$ years vs. $<65$ years), histology (squamous cell carcinoma, SCC vs. adenocarcinoma), tumor size ( $\geq 3 \mathrm{~cm}$ vs. $<3 \mathrm{~cm}$ ), and differentiation (poor vs. moderate/well). The results of pooled analyses are summarized in Table 3. The combined data showed that GLUT1 expression significantly correlated with male sex
Study

ID

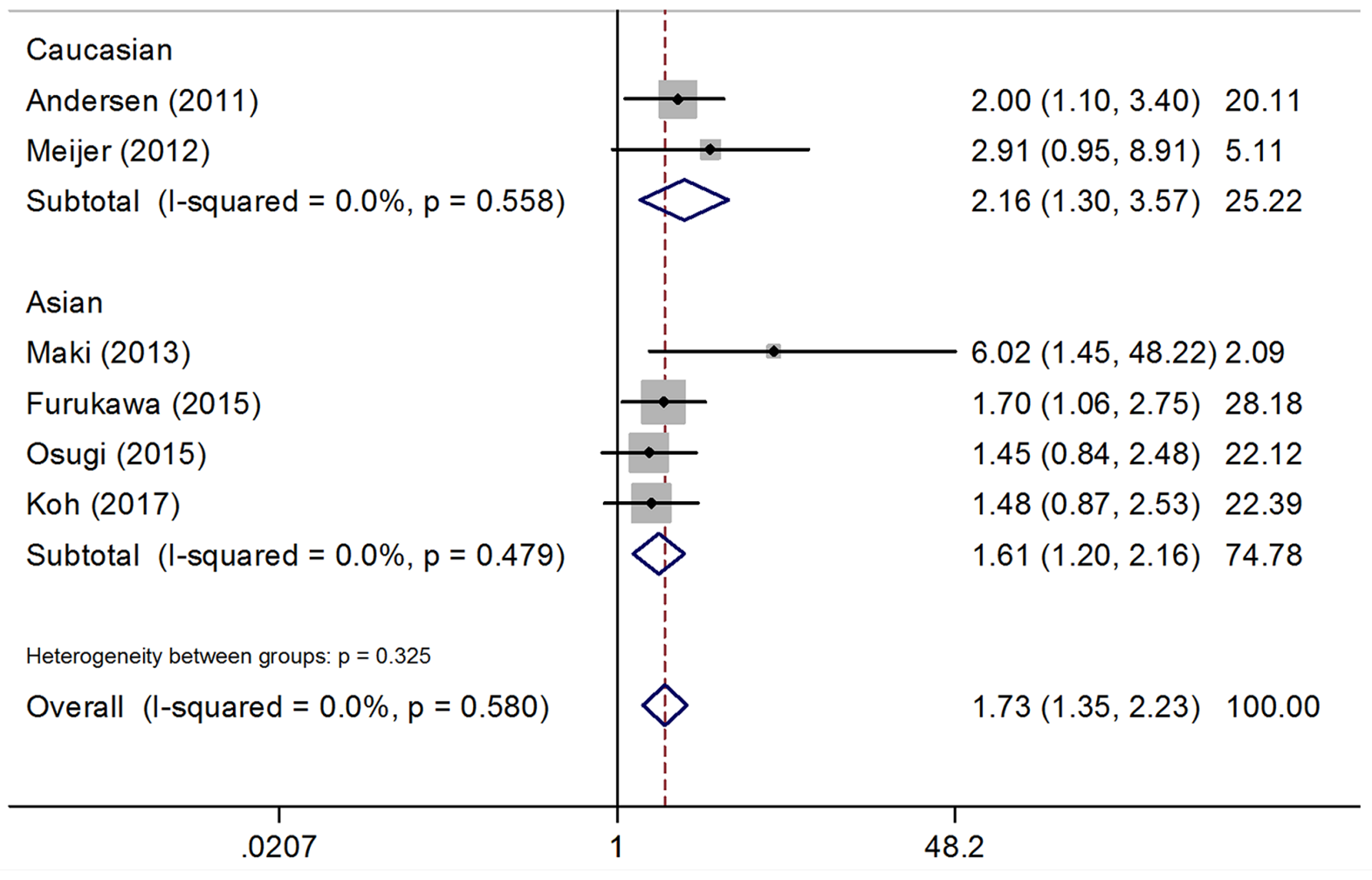

Figure 3: Forest plot of the association between GLUT1 and DFS, subgroup analysis was stratified by ethnicity. 
Table 3: Association between GLUT1 and clinicalpathological characteristics.

\begin{tabular}{|c|c|c|c|c|c|c|c|c|}
\hline \multirow[t]{2}{*}{ Variables } & \multirow{2}{*}{$\begin{array}{l}\text { No. of } \\
\text { studies }\end{array}$} & \multirow{2}{*}{$\begin{array}{c}\text { No. of } \\
\text { patients }\end{array}$} & \multirow{2}{*}{$\begin{array}{l}\text { Effects } \\
\text { model }\end{array}$} & \multirow{2}{*}{$\begin{array}{c}\text { OR } \\
(95 \% \mathrm{CI})\end{array}$} & \multirow[t]{2}{*}{$\mathbf{p}$} & \multicolumn{2}{|c|}{ Heterogeneity } & \multirow{2}{*}{$\begin{array}{l}\text { Publication } \\
\text { bias Begg's p }\end{array}$} \\
\hline & & & & & & $I^{2}(\%)$ & $\mathbf{P}_{\mathrm{h}}$ & \\
\hline Gender (male vs. female) & 5 & 721 & REM & $\begin{array}{c}2.29(1.17- \\
4.49)\end{array}$ & 0.015 & 69.5 & 0.011 & 1 \\
\hline Tumor stage (III-IV vs. I - II) & 5 & 885 & FEM & $\begin{array}{l}2.46(1.79- \\
3.38)\end{array}$ & $<0.001$ & 49.7 & 0.093 & 0.221 \\
\hline Age (years, $\geq 65$ vs. $<65$ ) & 4 & 606 & FEM & $\begin{array}{l}1.24(0.9- \\
1.72)\end{array}$ & 0.19 & 8.9 & 0.349 & 0.734 \\
\hline $\begin{array}{l}\text { Histology } \\
\text { (SCC vs. adenocarcinoma) }\end{array}$ & 4 & 616 & FEM & $\begin{array}{l}6.99(4.71- \\
10.38)\end{array}$ & $<0.001$ & 50 & 0.112 & 0.308 \\
\hline Tumor size ( $\geq 3 \mathrm{~cm}$ vs. $<3 \mathrm{~cm})$ & 3 & 323 & FEM & $\begin{array}{l}2.77(1.73- \\
\quad 4.44)\end{array}$ & $<0.001$ & 0 & 0.48 & 1 \\
\hline $\begin{array}{l}\text { Differentiation } \\
\text { (poor vs. moderate/well) }\end{array}$ & 3 & 333 & REM & $\begin{array}{l}1.03(0.15- \\
6.96)\end{array}$ & 0.976 & 91.8 & $<0.001$ & 0.602 \\
\hline
\end{tabular}

Abbreviations: REM, random-effects model; FEM, fixed-effects model; SCC, squamous cell carcinoma.

$(\mathrm{OR}=2.29 ; 95 \% \mathrm{CI}, 1.17-4.49 ; \mathrm{p}=0.015)$, advanced tumor stage $(\mathrm{OR}=2.46 ; 95 \% \mathrm{CI}, 1.79-3.38 ; \mathrm{p}<0.001)$, histology $(\mathrm{OR}=6.99 ; 95 \% \mathrm{CI}, 4.71-10.38 ; \mathrm{p}<0.001)$, and large tumor size $(\mathrm{OR}=2.77 ; 95 \% \mathrm{CI}, 1.73-4.44 ; \mathrm{p}$ $<0.001$ ) (Table 3). However, there was no significant connection between GLUT1 expression and age (OR = $1.24 ; 95 \% \mathrm{CI}, 0.9-1.72 ; \mathrm{p}=0.19)$ or differentiation (OR $=1.03 ; 95 \%$ CI, 0.15-6.96; $\mathrm{p}=0.976)$.

\section{Publication bias}

Begg's funnel plot was carried out to assess publication bias. The p-values of Begg's test for analysis of OS and DFS were 0.386 and 0.133 , respectively. Moreover, the funnel plots (Figure 4) were visually symmetrical. The Begg's p-values for analysis of clinicopathological parameters were greater than 0.05
(Table 3). Therefore, there was no evidence of significant publication bias in this meta-analysis.

\section{DISCUSSION}

A number of studies have explored the prognostic significance of GLUT1 in NSCLC; however, results have been inconsistent, which prompted this meta-analysis to obtain an objective view of this issue. The present meta-analysis extracted data from 10 eligible studies for the association of GLUT1 expression with OS, DFS, and clinicopathological characteristics. The results demonstrated that GLUT1 was an indicator for worse OS and DFS. In addition, GLUT1 expression significantly correlated with sex, tumor stage, histology, and tumor size in patients with NSCLC. These results suggest that
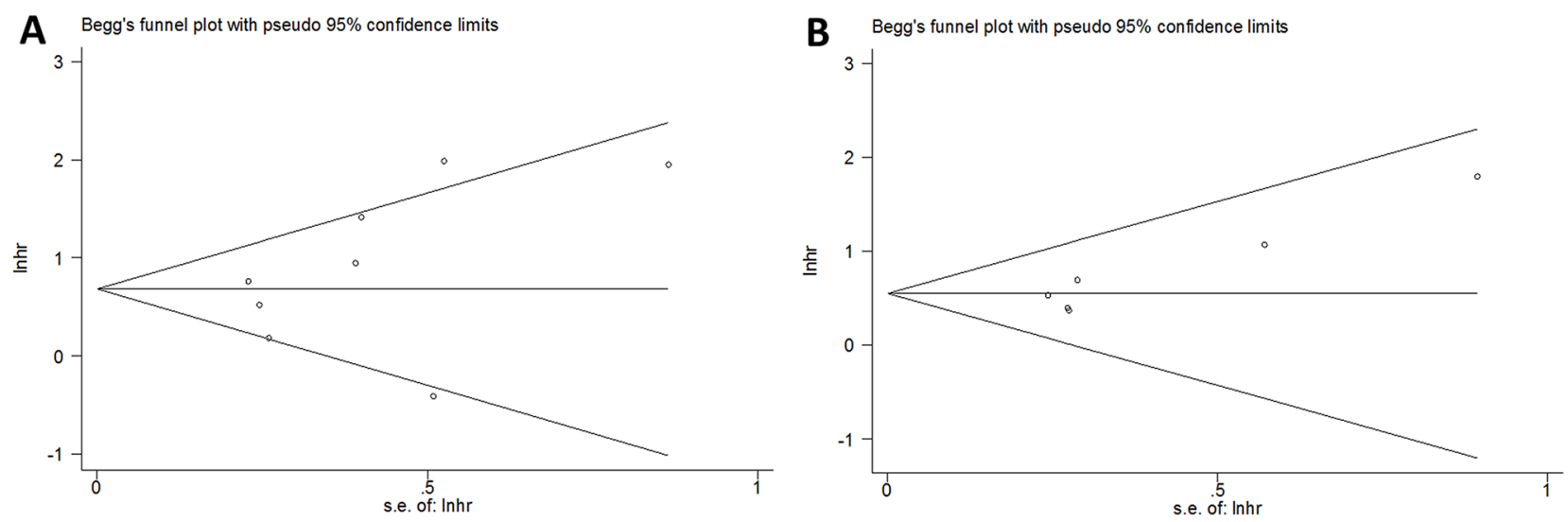

Figure 4: Publication bias tested by Begg's funnel plot for (A) OS, p=0.386 and (B) DFS, p=0.133. 
GLUT1 could act as a risk factor involved in aggressive biological behaviors of tumor cells, and a predictor of shortened survival of NSCLC patients.

GLUT1 is a key rate-limiting factor in the transport and metabolism of glucose in cancer cells [20]. Cancer cells are highly proliferative due to disease progression. In various cancers, hypoxia often occurs when tumor cells outstrip their vasculature [6]. Therefore, genes regulating glycolysis and glucose transport are activated to provide energy [21]. GLUT1 overexpression was found in a series of solid tumors,[6] and the prognostic value of GLUT1 for survival has also been reported. Jans et al. [22] showed that the presence of cytoplasmic GLUT-1 was a prognosticator for shorter recurrencefree survival in prostate cancer patients. Kunkel et al. [23] indicated that GLUT1 was a significant negative biomarker of OS in patients with oral squamous cell carcinoma. Moreover, Amann et al. [20] found that GLUT1 expression was increased in hepatocellular carcinoma, and was associated with advanced tumor stages. In the current meta-analysis, we found that high GLUT1 expression was connected with poor OS and DFS in NSCLC, which was consistent with previous findings in other types of cancer [9, 20, 22, 23]. To our knowledge, this is the first meta-analysis of the prognostic value of GLUT1 in NSCLC. Furthermore, we also demonstrated that GLUT1 was associated with advanced tumor stage and large tumor size. This association may be due to advanced stage and large tumors have high rates of glucose metabolism needed for energy production and therefore necessitating extensive overexpression and activation of GLUT1.

To guarantee study homogeneity, we only included studies using IHC to detect GLUT1 expression. We also noted that one study reported GLUT1 gene amplification to be significantly correlated with shorter survival in lung cancer patients $(\mathrm{p}<0.01)$ [24], and remained a statistically significant prognostic factor in a multivariate analysis. These findings are consistent with our results that demonstrate histological expression of GLUT1 as a prognostic biomarker of survival. Taken together, the results suggest that high GLUT1 expression at both transcript and protein levels have prognostic value.

Several limitations must be taken into account in this meta-analysis. First, significant heterogeneity was observed for the analysis of GLUT1 and OS. Specifically, substantial heterogeneity was found in the OS analysis in general and in the subgroup of Asian ethnicity. Although we selected eligible studies using uniform criteria, heterogeneity still existed in the primary studies. Second, the included studies were classified as Asian and Caucasian groups regarding ethnicity; however, in the Asian group, all studies were from one Asian country, Japan. Therefore, the Asian subgroup could be overrepresented, because other Asian countries such as China and Korea were not included. Studies from other
Asian countries are needed for a comprehensive evaluation of GLUT1 expression in NSCLC. Third, the relationship between GLUT1 expression and survival according to histological types was not analyzed in this meta-analysis. However, of the analyzed studies, two $[10,17]$ included only adenocarcinoma, whereas the remaining [11-16, 18, 19] included patients with different histological types. The survival outcomes of different histologic types could not be extracted because of insufficient data.

In summary, this meta-analysis showed that GLUT1 overexpression was a biomarker of worse OS and DFS in NSCLC. In addition, elevated GLUT1 expression significantly correlated with advanced tumor stage and large tumor size. We conclude that GLUT1 may serve as a prognostic biomarker for NSCLC. However, because of some limitations, further large prospective studies are needed to validate our results.

\section{METHODS}

\section{Search strategy}

This study was performed in accordance with Preferred Reporting Items for Systematic Reviews and Meta-Analyses (PRISMA) guidelines [25]. The electronic databases of PubMed, Embase, and Web of Science were searched till February 2017. The following search terms were used; "glucose transporter-1", "GLUT-1", "SLC2A1", "non-small cell lung cancer", "NSCLC", "lung carcinoma", and "lung neoplasms". Furthermore, reference lists of relevant studies were checked for potential eligible studies.

\section{Inclusion and exclusion criteria}

Eligible studies must meet the following inclusion criteria: (1) the diagnosis of NSCLC was histopathologically proven; (2) GLUT1 expression was detected by IHC method; (3) the correlation between GLUT1 expression and OS or disease-free survival (DFS) was evaluated or sufficient data was provided for calculation; and (4) studies as full-text articles were published in English. The exclusion criteria were as follows: (1) reviews, meeting abstract, letters, or duplicate publications; (2) animal studies; and (3) studies with insufficient data.

\section{Data extraction and quality assessment}

Two investigators (ZBT and WXS) independently extracted the following information from eligible studies: first author's surname, publication year, study location, age, sample size, tumor stage, histological type, study design, detection method, survival outcomes measured, and study period. The qualities of included studies were evaluated according to the Newcastle-Ottawa Scale 
(NOS). A score of 0 - 9 was used to indicate the quality of each study, on basis of selection (0 - 4), comparability $(0-2)$, and outcome $(0-3)$. Studies labeled with $\geq 7$ were considered as high quality studies.

\section{Statistical analysis}

To evaluate the impact of GLUT1 expression on OS and DFS, hazard ratio (HR) with its relative 95\% confidence interval (CI) was used in combination as the effective measure. A pooled $\mathrm{HR}>1$ indicated a worse OS/ DFS in high GLUT1 expressing patients, and a pooled $\mathrm{HR}<1$ represented the opposite results. Odds ratios (ORs) and their 95\% CIs were used to assess the correlation between GLUT1 overexpression and clinicopathological variables, including sex, age, tumor stage, histology, tumor size, and differentiation. Heterogeneity across studies was evaluated using Cochran's Q test and $I^{2}$ statistics. An $I^{2}>50 \%$ and $\mathrm{p}$-value for heterogeneity $<0.10$ indicated significant heterogeneity, and a random-effects was used for calculations, otherwise, a fixed-effects model was adopted. Publication bias was evaluated using Begg's funnel plot. A p-value $<0.05$ was considered statistically significant. All statistical analyses were performed using Stata 12.0 software (Stata Corporation, College Station, TX, USA).

\section{Abbreviations}

Glucose transporter 1, GLUT1; Non-small cell lung cancer, NSCLC; Hazard ratio, HR; Odds ratio, OR; Confidence interval, CI; Overall survival, OS; Newcastle-Ottawa Scale, NOS; Immunohistochemistry, IHC; Preferred Reporting Items for Systematic Reviews and Meta-Analyses, PRISMA.

\section{Author contributions}

All authors contributed significantly to this work. ZBT and WXS designed the research study; ZBT, CY and WXS performed the research study and extracted the data; ZBT, XHZ and WXS analyzed the data; ZBT, PJZ, and WXS wrote and revised the manuscript, and CY, XHZ and PJZ prepared the Figures and Tables. All authors reviewed the manuscript. In addition, all authors approved the final draft.

\section{CONFLICTS OF INTEREST}

The authors have no conflicts of interest to disclose.

\section{REFERENCES}

1. Torre LA, Bray F, Siegel RL, Ferlay J, Lortet-Tieulent J, Jemal A. Global cancer statistics, 2012. CA Cancer J Clin. 2015; 65:87-108

2. Molina JR, Yang P, Cassivi SD, Schild SE, Adjei AA. Nonsmall cell lung cancer: epidemiology, risk factors, treatment, and survivorship. Mayo Clin Proc. 2008; 83:584-94.
3. Brahmer J, Reckamp KL, Baas P, Crinò L, Eberhardt WE, Poddubskaya E, Antonia S, Pluzanski A, Vokes EE, Holgado E, Waterhouse D, Ready N, Gainor J, et al. Nivolumab versus Docetaxel in Advanced SquamousCell Non-Small-Cell Lung Cancer. N Engl J Med. 2015; 373:123-35.

4. Maemondo M, Inoue A, Kobayashi K, Sugawara S, Oizumi S, Isobe H, Gemma A, Harada M, Yoshizawa H, Kinoshita I, Fujita Y, Okinaga S, Hirano H, et al, and North-East Japan Study Group. Gefitinib or chemotherapy for non-small-cell lung cancer with mutated EGFR. N Engl J Med. 2010; 362:2380-88.

5. Alberg AJ, Brock MV, Ford JG, Samet JM, Spivack SD. Epidemiology of lung cancer: Diagnosis and management of lung cancer, 3rd ed: American College of Chest Physicians evidence-based clinical practice guidelines. Chest. 2013; 143:e1S-29S.

6. Carvalho KC, Cunha IW, Rocha RM, Ayala FR, Cajaíba MM, Begnami MD, Vilela RS, Paiva GR, Andrade RG, Soares FA. GLUT1 expression in malignant tumors and its use as an immunodiagnostic marker. Clinics (Sao Paulo). 2011; 66:965-72.

7. Furuta E, Okuda H, Kobayashi A, Watabe K. Metabolic genes in cancer: their roles in tumor progression and clinical implications. Biochim Biophys Acta. 2010; 1805:141-152. https://doi.org/10.1016/j.bbcan.2010.01.005.

8. Thorens B, Mueckler M. Glucose transporters in the 21st Century. Am J Physiol Endocrinol Metab. 2010; 298:E141-45.

9. Younes M, Lechago LV, Somoano JR, Mosharaf M, Lechago J. Wide expression of the human erythrocyte glucose transporter Glut1 in human cancers. Cancer Res. 1996; 56:1164-67.

10. Minami K, Saito Y, Imamura H, Okamura A. Prognostic significance of p53, Ki-67, VEGF and Glut-1 in resected stage I adenocarcinoma of the lung. Lung Cancer. 2002; 38:51-57.

11. Andersen S, Eilertsen M, Donnem T, Al-Shibli K, Al-Saad $\mathrm{S}$, Busund LT, Bremnes RM. Diverging prognostic impacts of hypoxic markers according to NSCLC histology. Lung Cancer. 2011; 72:294-302.

12. Kaira K, Oriuchi N, Takahashi T, Nakagawa K, Ohde Y, Okumura T, Murakami H, Shukuya T, Kenmotsu H, Naito T, Kanai Y, Endo M, Kondo H, et al. LAT1 expression is closely associated with hypoxic markers and mTOR in resected non-small cell lung cancer. Am J Transl Res. 2011; 3:468-78.

13. Osugi J, Yamaura T, Muto S, Okabe N, Matsumura Y, Hoshino M, Higuchi M, Suzuki H, Gotoh M. Prognostic impact of the combination of glucose transporter 1 and ATP citrate lyase in node-negative patients with non-small lung cancer. Lung Cancer. 2015; 88:310-18.

14. Meijer TW, Schuurbiers OC, Kaanders JH, LooijenSalamon MG, de Geus-Oei LF, Verhagen AF, Lok J, van 
der Heijden HF, Rademakers SE, Span PN, Bussink J. Differences in metabolism between adeno- and squamous cell non-small cell lung carcinomas: spatial distribution and prognostic value of GLUT1 and MCT4. Lung Cancer. 2012; 76:316-23.

15. Sasaki H, Shitara M, Yokota K, Hikosaka Y, Moriyama S, Yano M, Fujii Y. Overexpression of GLUT1 correlates with Kras mutations in lung carcinomas. Mol Med Rep. 2012; 5:599-602.

16. Karpathiou G, Sivridis E, Koukourakis M, Mikroulis D, Bouros D, Froudarakis M, Bougioukas G, Maltezos E, Giatromanolaki A. Autophagy and Bcl-2/BNIP3 death regulatory pathway in non-small cell lung carcinomas. APMIS. 2013; 121:592-604.

17. Maki Y, Soh J, Ichimura K, Shien K, Furukawa M, Muraoka T, Tanaka N, Ueno T, Yamamoto H, Asano H, Tsukuda K, Toyooka S, Miyoshi S. Impact of GLUT1 and Ki-67 expression on early stage lung adenocarcinoma diagnosed according to a new international multidisciplinary classification. Oncol Rep. 2013; 29:133-40.

18. Furukawa T, Miyata Y, Kushitani K, Mimae T, Tsutani Y, Takeshima Y, Okada M. Association between [18F]-fluoro2-deoxyglucose uptake and expressions of hypoxia-induced factor $1 \alpha$ and glucose transporter 1 in non-small cell lung cancer. Jpn J Clin Oncol. 2015; 45:1154-61.

19. Koh YW, Lee SJ, Park SY. Differential expression and prognostic significance of GLUT1 according to histologic type of non-small-cell lung cancer and its association with volume-dependent parameters. Lung Cancer. 2017; 104:31-37.
20. Amann T, Maegdefrau U, Hartmann A, Agaimy A, Marienhagen J, Weiss TS, Stoeltzing O, Warnecke C, Schölmerich J, Oefner PJ, Kreutz M, Bosserhoff AK, Hellerbrand C. GLUT1 expression is increased in hepatocellular carcinoma and promotes tumorigenesis. Am J Pathol. 2009; 174:1544-52.

21. Chiche J, Brahimi-Horn MC, Pouysségur J. Tumour hypoxia induces a metabolic shift causing acidosis: a common feature in cancer. J Cell Mol Med. 2010; 14:771-94.

22. Jans J, van Dijk JH, van Schelven S, van der Groep P, Willems SH, Jonges TN, van Diest PJ, Bosch JL. Expression and localization of hypoxia proteins in prostate cancer: prognostic implications after radical prostatectomy. Urology. 2010; 75:786-92.

23. Kunkel M, Reichert TE, Benz P, Lehr HA, Jeong JH, Wieand S, Bartenstein P, Wagner W, Whiteside TL. Overexpression of Glut-1 and increased glucose metabolism in tumors are associated with a poor prognosis in patients with oral squamous cell carcinoma. Cancer. 2003; 97:1015-24.

24. Ogawa J, Inoue H, Koide S. Glucose-transporter-type-Igene amplification correlates with sialyl-Lewis-X synthesis and proliferation in lung cancer. Int J Cancer. 1997; 74:189-92.

25. Moher D, Liberati A, Tetzlaff J, Altman DG. Preferred reporting items for systematic reviews and meta-analyses: the PRISMA statement. Ann Intern Med. 2009; 151:264269, w264. 